\title{
Investment Performance in the Healthcare System by the Population Assessments
}

\author{
Nagimova Aysylu Mirzarifovna \\ Doctor of Social Sciences,Associate Professor of General Management, Institute of Management, \\ Economics and Finance, Kazan Federal University; Leading Researcher, High-quality research Department, \\ Center for Advanced Economic Research, Academy of Sciences of the Republic of Tatarstan; \\ nagais@mail.ru

\section{Zainullina Milyausha Rashitovna}

\begin{abstract}
PhD in Economic Sciences,Associate Professor of General Management, Institute of Management, Economics and Finance, Kazan Federal University; Head of Micro and Mezo-research Department, Center for Advanced Economic Research, Academy of Sciences of the Republic of Tatarstan; milyausha-zainul@list.ru/M.Zaynullina@tatar.ru
\end{abstract}

\section{Doi:10.5901/mjss.2014.v5n18p229}

\section{Abstract}

The article deals with the problem of investing in the healthcare system on the example of the Republic of Tatarstan, there is analyzed public opinion on the effectiveness of the healthcare system functioning as an indicator of the investment performance.

\section{Introduction}

One of the main tasks of the modern Russian social development is to improve the population quality of living, to enhance the living conditions of society in the long term. In this regard, Russia's particularly topical problems are to increase birthrate, life expectancy and generally improving the demographic situation. The most important tool to achieve these strategic objectives is to improve the quality of health services, the conditions of detention and treatment in hospitals and in general, to advance the system of healthcare provision for population. The main implementation mechanism of the healthcare system problems is an effective investment in this area. In the recent years, the federal government and the general governments in the Republic highlighted great importance to the activity that is expressed particularly in increasing the amount of investment in this area. However, the volumes of investments in the social sector are not always adequately reflected in the quality of living of citizens. Objective of our study was to investigate the investment performance in the health sector from the perspective of the main consumers - population.

\section{Materials and Methods}

Basic research methods for the investment performance in the health sector were the analysis methods of absolute and relative values of statistical indicators, the method of finding the average values of statistical indicators and questionnaire method. The aim of the study was to evaluate the investment performance in the healthcare through a comparative analysis of the results of the public opinion research about population satisfaction with the quality of medical services provided in state and municipal health institutes and statistic data for investments in these areas. We carried out a questionnaire survey of the population from 2005 to 2013 years in all administrative entities of the Republic of Tatarstan $(n-2186$ at each stage of the research) $[1,2,3]$. For the entire observation period were interviewed 13,116 persons. The sample population was formed by multi-staged regionalized quota sample. Representative sampling error was $5 \%$. The survey was conducted on the basis of structured interviews. In the article, there were analyzed statistical digests for 8 years period in the Republic of Tatarstan.

\section{Results and Discussion}

Healthcare system status of any region is closely connected to the general economic situation - the more developed 
region, the greater investment in health, it may direct. A major condition of dynamic economic growth is investment. We analyzed the main statistical indicators of investment in the economy in the Republic of Tatarstan for 2005-2012 years. As it can be seen from Figure 1, the overall investment dynamics during this period tends to increase. This means that the region has the investment attractiveness and develops dynamically. Slight decrease was observed in 2008-2009, due to the global economic crisis. The average value of the growth rate of investment in the economy amounted to $19.24 \%$ (Table 3.). Consequently, the economy of the region is in the process of expanded reproduction of the economic system (Figure 1).

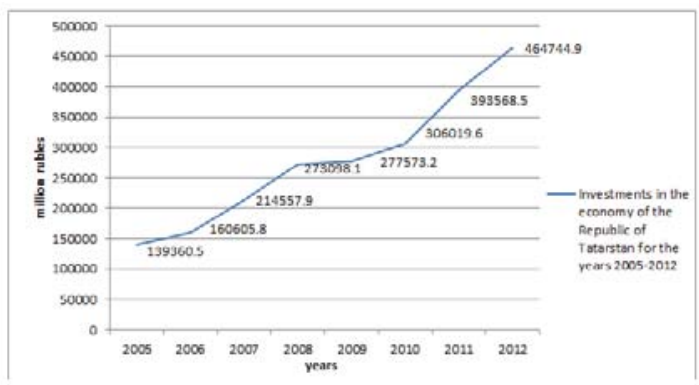

Figure 1: Investments in the economy of the Republic of Tatarstan for the years 2005-2012 (million rubles).

We wondered to what extent ordinary citizens feel economic success. Do they feel the output of investment growth? The results of our population study is quite sensitive to changes in the economy. Thus, in recent years there is evident the rise of positive assessments of the economic situation and the decline in the proportion of negative and neutral ratings. It is an interesting the fact that somehow reduction of investment in 2009 is promptly reflected on public opinion - in this period particularly there is a decrease of positive assessments of the economy for the entire observation period (Figure 2).

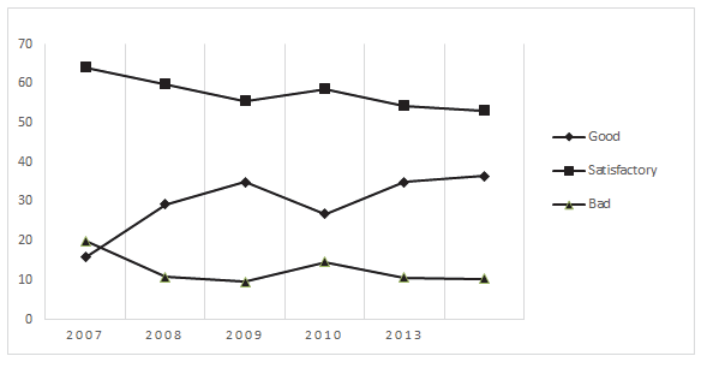

Figure 2: Distribution of respondent answers to the question "How do you assess the current economic situation of your location (city, village, etc.)?" (in percentage)

Let us consider the dynamics of investment in the healthcare system. Investments in the health have shown slowdown in the rate of growth in the years 2006, 2008, 2010 on 24.2\%, 17.27\%, 8.39\%, respectively (Table 3). In 2007, 2009, 2011, 2012 there was an increase of the growth rate for investments on $13.13 \% 25.6 \% ; 84 \%, 10.75 \%$, respectively (Table 3). The highest growth was observed in 2011 - 84\%. This was due to government programs for health development of the Russian Federation. Remodelling of health facilities was heavily invested. This policy was maintained in 2012 too. However, the cost in 2012 increased at a slower rate. Average growth rate of investments amounted to $11.96 \%$ (Table 3); which is below the average growth rate in the economy almost doubled (Table 3). 
Table 1. Investments in education and healthcare in absolute and relative terms in the Republic of Tatarstan

\begin{tabular}{|l|c|c|c|c|c|c|c|c|}
\hline & 2005 & 2006 & 2007 & 2008 & 2009 & 2010 & 2011 & 2012 \\
\hline Investments in health and social services, million rubles. & 6845.5 & 5188.8 & 5870.2 & 4856 & 6103.2 & 5590.7 & 10288.6 & 11395.6 \\
\hline Investments in health and social services, in\% to total & 4.9 & 3.2 & 2.7 & 1.8 & 2.2 & 1.8 & 2.6 & 2.4 \\
\hline All investments in the economy, in million rubles. & 139360.5 & 160605.8 & 214557.9 & $273,098.1$ & 277573.2 & 306 & 019.6 & 393568.5 \\
\hline All investments in the economy, in\% to total & 100 & 100 & 100 & 100 & 100 & 100 & 100 & 100 \\
\hline
\end{tabular}

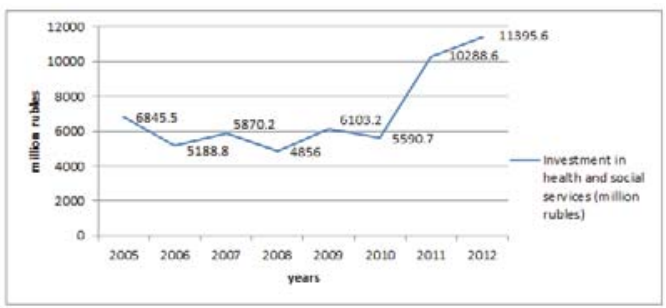

Figure 3: Investment in health and social services (million rubles).

Table 2. Investment growth in the economy and healthcare in the Republic of Tatarstan (in percentage)

\begin{tabular}{|l|c|c|c|c|c|c|c|}
\hline & $2006 / 2005$ & $2007 / 2006$ & $2008 / 2007$ & $2009 / 2008$ & $2010 / 2009$ & $2011 / 2010$ & $2012 / 2011$ \\
\hline Investments in health and social services & 75.79 & 113.13 & 82.72 & 125.68 & 91.60 & 184.03 & 110.75 \\
\hline All investments in the economy & 115.24 & 133.59 & 127.28 & 101.63 & 110.24 & 128.60 & 118.08 \\
\hline
\end{tabular}

Table 3. Growth rate of investment in the economy and healthcare and the average growth rate of investment in the economy and healthcare in the Republic of Tatarstan (in percentage)

\begin{tabular}{|l|c|c|c|c|c|c|c|c|}
\hline & $2006 / 2005$ & $2007 / 2006$ & $2008 / 2007$ & $2009 / 2008$ & $2010 / 2009$ & $2011 / 2010$ & $2012 / 2011$ & $\begin{array}{c}\text { Average } \\
\text { rate growth }\end{array}$ \\
\hline Investments in Health and social services & -24.20 & 13.13 & -17.27 & 25.68 & -8.39 & 84.03 & 10.75 & 11.96 \\
\hline All investment in the economy & 15.24 & 33.59 & 27.28 & 1.63 & 10.24 & 28.60 & 18.08 & 19.24 \\
\hline
\end{tabular}

Analysis of public opinion regarding the status of the healthcare system shows the corresponding results. As we can see in the previous diagram, since 2011 investment in public health has quite significantly increased and we observe a decline in the share of negative assessments of the respondents (Figure 4).

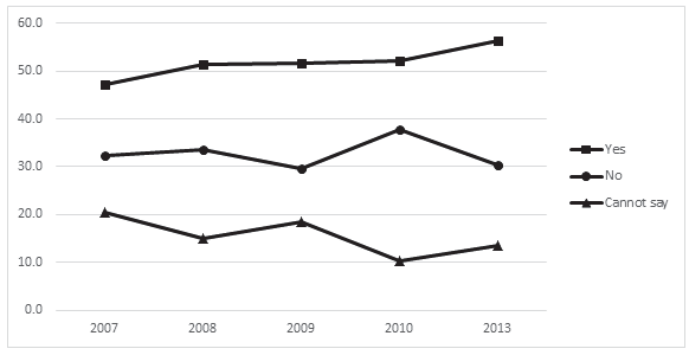

Figure 4: Distribution of respondent answers to the question: "Are you satisfied with the state of medical service in your community?" (in percentage)

However, together with a quite marked increase of investment in the healthcare system this upswing of positive ratings $(4 \%)$ is not sufficiently revealing. Explanation of the situation could be found in a more detailed study of the problem. What are the causes for more than a modest assessment of the healthcare system from the population view 
with increasing of the investment amount in the background? Let us consider the opinion of the population regarding ambulatory and hospital medical service.

At all stages of the major problems that are under observation there were the issues of organizational and technical nature in the hospital service for the population - queues for admission to the local therapist, difficulties of getting an appointment to a specialized doctor, lack of equipment for examination and others (Figure 5).

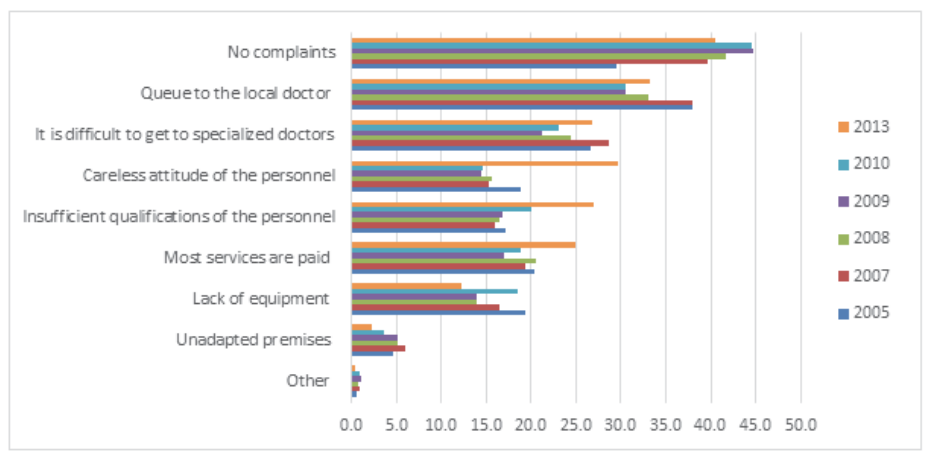

Figure 5: Distribution of respondent answers to the question: "How would you assess the quality of medical service for the population in polyclinics?" (in percentage)

A similar situation is observed in the hospital service for the population - in 2005-2007, the main problems were the lack of equipment and drugs in hospitals, lack of places to hospitalization, poor nutrition, etc. (Figure 6).

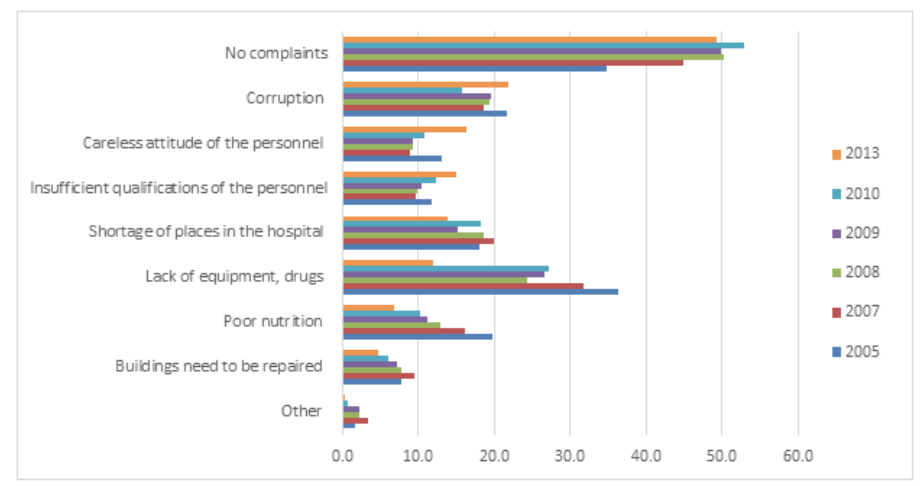

Figure 6: Distribution of respondent answers to the question: "How would you assess the quality of medical service for the population in hospitals?" (in percentage)

Alongside with the expansion of the investment volumes we managed to solve a number of problems related to material support to medical assistance system for the population. High-tech equipment was purchased, including small regional hospitals, and provision of medicines was improved. Reforming of the healthcare system allowed to concentrate material and human resources at district hospitals capable of providing multi-disciplinary professional assistance. In the meantime, in this positive background, the group of problems related to the human factor has escalated. High-tech medicine has often become inaccessible due to the inability of doctors to work on sophisticated equipment - and population expressed dissatisfaction with the level of medical personnel. Frequent criticism caused the attitude of medical staff to patients, expressed in carelessness and sometimes even indifference and rudeness towards people. In addition, a large number of services are given only on a fee basis. The participants of the survey expressed in a greater degree dissatisfaction with the corruption in the healthcare system. 


\section{Conclusion}

Thus, we can conclude that, despite the generally positive result, investment in healthcare has not achieved the intended effect, as it decided only logistical side of the problem, without affecting the human factor. Financial inflow did not lead to an automatic increase of medical personnel qualification, was unable to resolve the issue of staff attitude to patients, did not contribute to reduce the level of corruption in this sphere. Consequently, investment in healthcare of the republic has not fully achieved the set goal - to improve the quality of medical population services, and therefore has not provided to improvement of the life quality of citizens.

\section{References}

Nagimova A. M. Population satisfaction of the Republic of Tatarstan, the main components of quality of living and the ongoing social and economic reforms (comparative analysis 2005, 2007, 2008, 2009, 2010.). Kazan, 2011. P. 80.

Nagimova A.M., Nugaev M.A. Role and place of healthcare in ensuring the life quality for population in the region. Newsletter of economics, law and sociology. - 2010. - № 2. - P.118-122.

Safiullin M.R., Nagimova A.M., Zainullina M.R. and others. Report about the main trends of Socio - Economic Development in the Republic Tatarstan in 2012. Kazan: - "Artifact Publication", 2013. P.86.

Zainullina M.R. Problems of investment attractiveness in the Russian Federation market. Socio - economic problems of formation and development in the market economy. (Conference) Kazan: - in KSFEI - 2011 - P.128-130.

Zainullina M. P. Small business effectiveness by territorial grounds and its investment activities. Electronic economic newsletter of Tatarstan for the 2nd quarter of 2013.

Republic of Tatarstan, Statistical Yearbook, 2005. Publ: Tatarstanstat, g.Kazan, 2006. C. 433-436.

Republic of Tatarstan, Statistical Yearbook, 2006 year. Publ: Tatarstanstat, g.Kazan, 2007. C. 433-436.

Republic of Tatarstan, Statistical Yearbook, 2007 year. Publ: Tatarstanstat, g.Kazan, 2008. C. 433-436.

Republic of Tatarstan, Statistical Yearbook, 2008 year. Publ: Tatarstanstat, g.Kazan, 2009. C. 433-436.

Republic of Tatarstan, Statistical Yearbook, 2009 year. Publ: Tatarstanstat, g.Kazan, October 20. C. 477-479.

Republic of the Tatarstan region, Statistical Yearbook, 2010 year. Publ: Tatarstanstat, g.Kazan, 2009. C. 451 -4 53.

Republic of Tatarstan, statistically s Yearbook, 2011 year. Publ: Tatarstanstat, g.Kazan, 2012. C. 433-436.

Republic of Tatarstan, Statistical Yearbook, 2012. Publ: Tatarstanstat, g.Kazan, 2013. C. 257-259. 
